\title{
n/p/n Tunnel Junction InGaAs Monolithic Interconnected Module (MIM)
}

\author{
David M. Wilt \\ NASA Glenn Research Center \\ Cleveland, $\mathrm{OH}$ \\ Christopher S. Murray \\ Bechtel Bettis Inc. \\ West Mifflin, PA
}

\author{
Navid S. Fatemi \\ Emcore Inc. \\ Albuquerque, NM
}

\author{
Victor Weizer \\ Essential Research, Inc. \\ Cleveland, $\mathrm{OH}$
}

\begin{abstract}
The Monolithic Interconnected Module (MIM), originally introduced at the First NREL thermophotovoltaic (TPV) conference, consists of low-bandgap indium gallium arsenide (InGaAs) photovoltaic devices, series interconnected on a common semi-insulating indium phosphide (InP) substrate. An infrared reflector is deposited on the back surface of the substrate to reflect photons, which were not absorbed in the first pass through the structure. The single largest optical loss in the current device occurs in the heavily doped $p$-type emitter. A new MIM design (pat. pend.) has been developed which flips the polarity of the conventional MIM cell (i.e., n/p rather than $p / n$ ), eliminating the need for the high conductivity $p$-type emitter. The $p$-type base of the cell is connected to the n-type lateral conduction layer through a thin InGaAs tunnel junction. $0.58 \mathrm{eV}$ and $0.74 \mathrm{eV}$ InGaAs devices have demonstrated reflectances above $90 \%$ for wavelengths beyond the bandgap ( $>95 \%$ for unprocessed structures). Electrical measurements indicate minimal voltage drops across the tunnel junction $(<3 \mathrm{mV} / \mathrm{junction}$ under $1200 \mathrm{~K}$-blackbody illumination) and fill factors that are above $70 \%$ at current densities $\left(J_{s c}\right)$ above $8 \mathrm{~A} / \mathrm{cm}^{2}$ for the $0.74 \mathrm{eV}$ devices.
\end{abstract}

\section{Introduction}

In thermophotovoltaic (TPV) energy conversion, a radiator is heated to incandescence and a photovoltaic device is placed in view of the radiator to convert the radiant energy into electrical energy. Research in TPV has been renewed recently due to the development of new radiator, filter and photovoltaic cell technologies [1]. Most current efforts in TPV research have concentrated on using front surface spectral control elements such as selective emitters (radiators) [2] or greybody radiators combined with plasma, dielectric or dipole filters [3,4] in order to improve system efficiency. The front-surface spectral control approach generally produces systems with lower power densities $\left(\mathrm{W} / \mathrm{cm}^{2}\right)$.

A different approach involves the use of rear-surface spectral controls. Using this technique, the entire radiant output from the radiator is incident upon the photovoltaic (PV) device, thereby providing higher output power densities. Photons that the PV device is unable to convert pass through the cell structure and reflect off of a rear reflector back to the radiator for recuperation. Researchers have developed TPV cells that utilize low-doped substrates and reflective rear contacts to provide photon recuperation $[5,6]$.

A Monolithic Interconnected Module, or MIM, TPV cell design, originated at NASA Lewis Research Center [3], takes a different approach to rear surface spectral control. The device consists of series-connected indium gallium arsenide (InGaAs) devices on a common, semi-insulating indium phosphide ( $\operatorname{lnP}$ ) substrate. An infrared reflector is deposited on the rear surface of the InP substrate to reflect photons back toward the front surface of the cell. This provides a second pass opportunity for photons capable of being converted by the cell. In addition, long wavelength photons are returned to the radiator for "recuperation", improving the system efficiency. 
The MIM design offers several advantages. Firstly, small series-connected cells provide high voltages and low currents, reducing $I^{2} R$ losses. In addition, the small size of the cells permits an array to be comprised of series/parallel strings rather than a single series-connected string of larger cells. This should improve the reliability of the TPV module since the failure of a single cell would not debilitate the entire array. Also, the cell size and distribution may be easily adjusted to minimize the losses associated with radiator non-uniformity (i.e., variation in view factor, temperature, etc.).

The MIM design maximizes output power density since losses associated with front-surface spectral controls are eliminated. The lack of front surface spectral control represents a significant simplification of TPV system design and thermal management, as there are no filters to cool. In addition, the rear surface of the device is not electrically active, therefore the cell may be directly bonded to the substrate/heat sink without concern for electrical isolation. This greatly simplifies the array design and improves the thermal control of the cells. Lastly, photons that are weakly absorbed have the possibility of multiple passes through the cell structure. This feature is particularly important for lattice-mismatched devices, where poor minority carrier diffusion length can be partially offset by making the cell thin, forcing the carrier generation to occur closer to the $\mathrm{p} / \mathrm{n}$ junction.

Although the MIM design has many beneficial attributes, there are limitations. The optical efficiency of the conventional MIM design [7] and interdigitated MIM design, developed by NREL [8], suffer from free carrier absorption losses in the heavily doped p-type InGaAs emitter. The trade off between optical and electrical losses forces a balance of emitter thickness and doping level. To date, most devices have utilized heavily doped $\left(>1 \times 10^{19} \mathrm{~cm}^{-3}\right)$ emitters of approximately $0.1 \mu \mathrm{m}$ in thickness. This layer accounts for the majority of the optical losses in the MIM for unprocessed structures. Recent Monte Carlo photonic modeling, being presented at this conference [9], suggests that the processing techniques used can also have a significant affect on the amount of photons that can be recuperated at the radiator. Four areas of particular concern are the specular/diffuse reflectance of the BSR, light trapping due to surface features (i.e., isolation trenches), the reflectance of the electrical metallization at the metal semiconductor interface, and IR absorption in the anti-reflective coatings.

\section{Cell Description}

In order to optimize the optical efficiency of the MIM device, it is desirable to minimize the thickness of heavily doped $p$-type material. P-type material has exhibited $\sim 20 \mathrm{x}$ higher free carrier absorption compared to similarly doped $n$-type InGaAs. Converting the photovoltaic device polarity from $p$ on $n(p / n)$ to $n / p$ allows the use of $n$-type material for the emitter. In addition to reducing the optical losses, majority carriers in the n-type emitter have approximately $25 x$ higher mobility than p-type material, leading to lower resistive and grid shadowing losses.

It is also desirable to use n-type material for the lateral conductor layer (LCL) in order to minimize electrical and optical losses. This layer conducts the collected carriers to the interconnect (in the case of the conventional MIM design) or to the closest back contact (in the case of the interdigitated MIM). The use of $p$-type material for this layer imposes significant optical and electrical losses. Therefore, we employ a thin InGaAs tunnel junction (TJ) to connect the p-type base to the $n$-type LCL. The complete device structure for $0.74 \mathrm{eV}$ InGaAs is shown in Figure 1. For use in lattice-mismatched InGaAs, a suitable buffer layer would be inserted between the substrate and the active device. The use of the $\mathrm{n} / \mathrm{p} / \mathrm{n}$ TJ MIM structure is applicable to both the conventional and interdigitated MIM configurations.

\section{Tunnel Junction Development}

Successful development of the tunnel junction (TJ) MIM requires the development of a thin, high conductance tunnel junction. Test TJ devices were fabricated using a low-pressure Organo-Metallic Vapor Phase Epitaxy (OMVPE) reactor. Tunnel junction structures were produced using both $0.74 \mathrm{eV}$ and $0.60 \mathrm{eV}$ InGaAs. $150 \mu \mathrm{m}$ diameter test diodes were fabricated for characterization with TJ layer thickness' from $200 \AA$ to $1 \mu \mathrm{m}$. Figure 2 shows the I-V characteristic of a $0.74 \mathrm{eV}$ InGaAs tunnel junction with $0.5 \mu \mathrm{m}$ layers. The TJ demonstrated 
excellent resistivity $\left(R_{\max }=3.7 \times 10^{-4} \mathrm{ohm}-\mathrm{cm}^{2}\right)$ and current carrying capability $\left(J_{p}=1900 \mathrm{~A} / \mathrm{cm}^{2}\right)$. Tunnel junctions fabricated from $0.6 \mathrm{eV}$ InGaAs also demonstrated excellent I-V characteristics $\left(J_{\mathrm{p}}=700 \mathrm{~A} / \mathrm{cm}^{2}, R_{\max }=5.6 \times 10^{-4}\right.$ ohm- $\left.\mathrm{cm}^{2}\right)$. Perfect $0.6 \mathrm{eV}$ devices $(\mathrm{QE}=1$ ) fabricated using these tunnel junctions could expect to lose 2.4 $\mathrm{mV} / \mathrm{junction}$ under a $1200 \mathrm{~K}$ blackbody illumination (view factor $=1$ ).

\begin{tabular}{l}
\hline $0.1 \mu \mathrm{m} n+\operatorname{InGaAs}$ \\
\hline $0.1 \mu \mathrm{m} n+\operatorname{InP}$ \\
\hline $0.3 \mu \mathrm{m} n+\operatorname{InGaAs}$ \\
\hline $1.5 \mu \mathrm{m} p \operatorname{InGaAs}$ \\
\hline $0.1 \mu \mathrm{m} p+\operatorname{InP}$ \\
\hline $500 \AA \mathrm{p}+\operatorname{InGaAs}$ \\
\hline $500 \AA \mathrm{n}++\operatorname{InGaAs}$ \\
\hline $0.1 \mu \mathrm{m} n+\operatorname{InP}$ \\
\hline $1.0 \mu \mathrm{m} n+\operatorname{InGaAs}$ \\
\hline InP:Fe
\end{tabular}

Contact Layer

Front Window

Emitter

Base

Back Window

Tunnel Junction

Etch St op

Lateral Conduction Layer

Substra te

Figure 1 - Test structure for $0.74 \mathrm{eV}$ InGaAs n/p/n TJ MIM (conventional).

Next, tunnel junction test structures were grown with the appropriate over-layer thickness of InGaAs. This was done so that the effects of an extended temperature soak on dopant distribution within the tunnel junction were appropriately considered. Three test $\mathrm{n} / \mathrm{p} 0.74 \mathrm{eV}$ cell structures were fabricated and tested. Two of them n/p/n structures that had tunnel junctions with layer thickness of $1000 \AA$ and $500 \AA$. The third was a control structure, which had the same $n / p$ cell layers, but deposited on a $p$-type substrate. The I-V tests of these structures were identical, indicating that the tunnel junction was not negatively impacting the device operation.

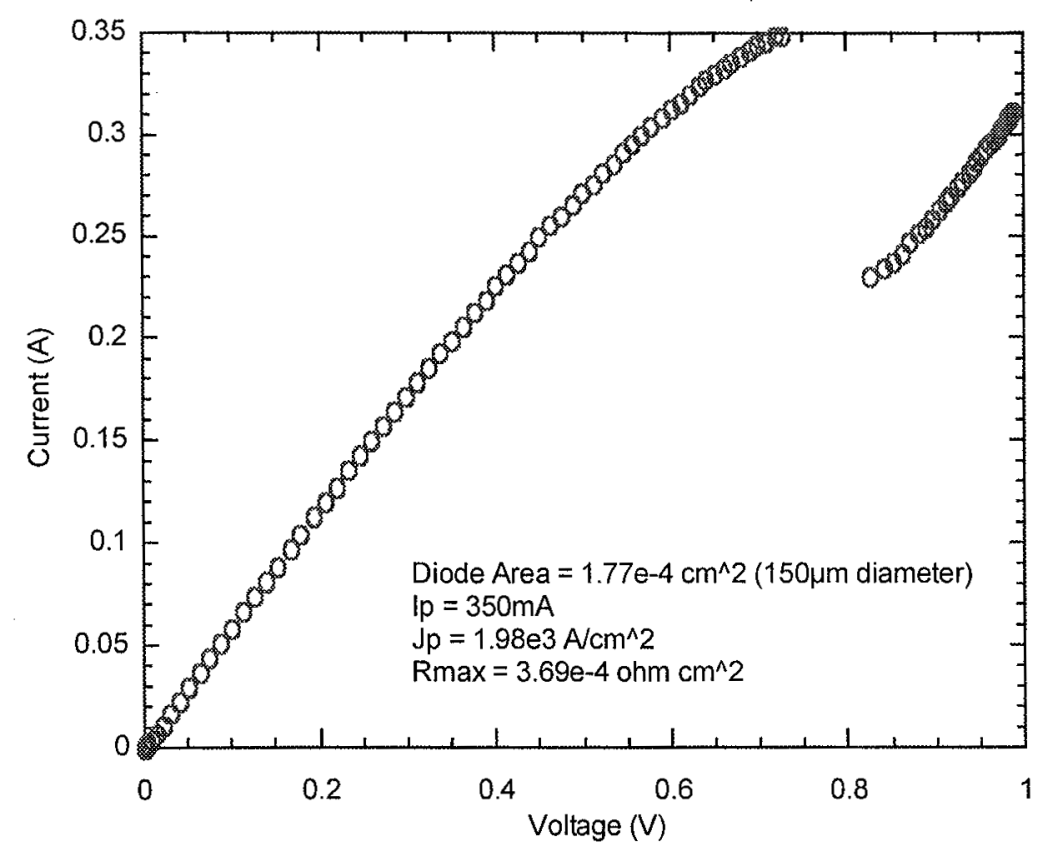

Figure 2 - I-V characteristic of tunnel junction fabricated from $0.74 \mathrm{eV}$ InGaAs. 


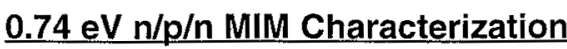

Verification of the $n / p / n$ cell concept was accomplished by fabricating the test device structure shown in figure 1 . Figure 3 shows the variation of fill factor with current density for this structure compared to several conventional $\mathrm{p} / \mathrm{n}$ structures. The $\mathrm{n} / \mathrm{p} / \mathrm{n}$ device was processed using our standard contact design for $\mathrm{p} / \mathrm{n} \mathrm{MIM}$ devices. All of the devices had the same LCL thickness and doping level. The differences in FF can be attributed to variations in the emitter type, doping level and thickness.

Measurements were taken in a flash simulator with the cell at room temperature. As shown in the data, there is very little reduction in FF as the current density is increased for the $n / p / n$ device, whereas the $p / n$ structures all show significant degradation with increasing intensity. For operation of this device under a $1200 \mathrm{~K}$ radiator, it is expected that the current density would not exceed $0.9 \mathrm{~A} / \mathrm{cm}^{2}$. Thus, there is ample opportunity to reduce layer thickness', doping levels and grid coverage without sacrificing electrical performance. This optimization was not performed because the bandgap of this device is too high for the illumination source of interest.

Figure 4 shows the reflectance measurements for an $\mathrm{n} / \mathrm{p} / \mathrm{n}$ device structure (NAS468 - not a processed device) similar to that shown in Figure 1. The principle differences are a reduction in the thickness of the tunnel junction layers from $500 \AA$ to $100 \AA$, and a reduction in the $\mathrm{LCL}$ thickness from $1.0 \mu \mathrm{m}$ to $0.15 \mu \mathrm{m}$. There is also a reduction in the doping level of the LCL. from $3 \times 10^{19} \mathrm{~cm}^{-3}$ to the low $10^{18} \mathrm{~cm}^{-3}$ range. This structure is suitable for fabrication into an interdigitated MIM device.

For comparison, a conventional $\mathrm{p} / \mathrm{n}$ MIM structure reflectance is also plotted (NAS445). There are two features of significance in this figure, the elimination of the plasma absorption peaks at approximately $6 \mu \mathrm{m}$ and $9 \mu \mathrm{m}$ and the increase in reflectance in the short wavelength region. The elimination of the plasma peaks can be attributed to the interdigitated cell design with it's lower doped LCL. This feature is not specific to the $\mathrm{n} / \mathrm{p} / \mathrm{n}$ design. The increase in the short wavelength reflectance from $\sim 0.88$ to $\sim 0.95$ is a direct result of the elimination of the heavily doped $\mathrm{p}$-type emitter through the $\mathrm{n} / \mathrm{p} / \mathrm{n}$ design.

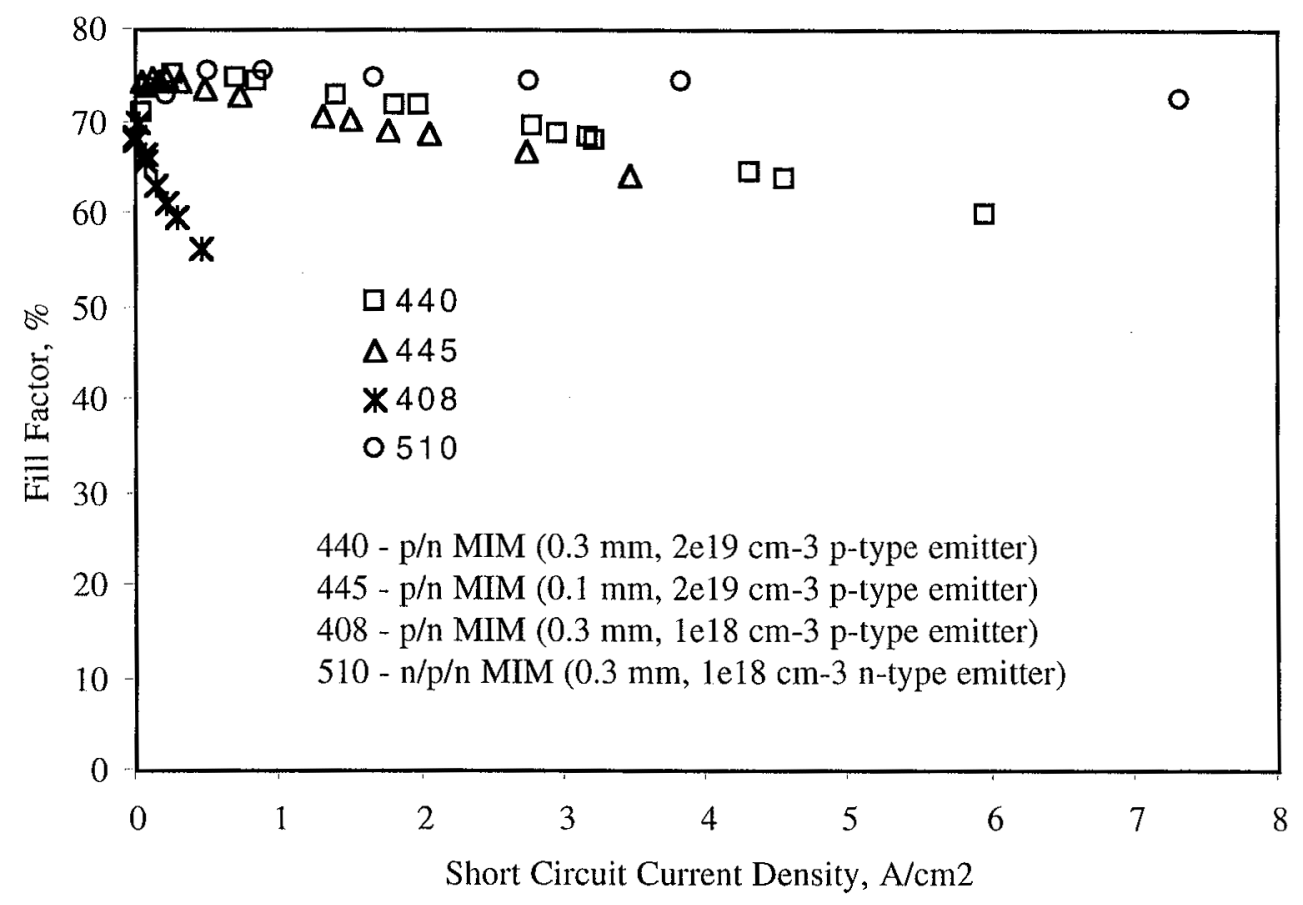

Figure 3 - Variation in fill factor with current density for the $\mathrm{n} / \mathrm{p} / \mathrm{n} 0.74 \mathrm{eV}$ MIM with the architecture shown in Figure 1. 


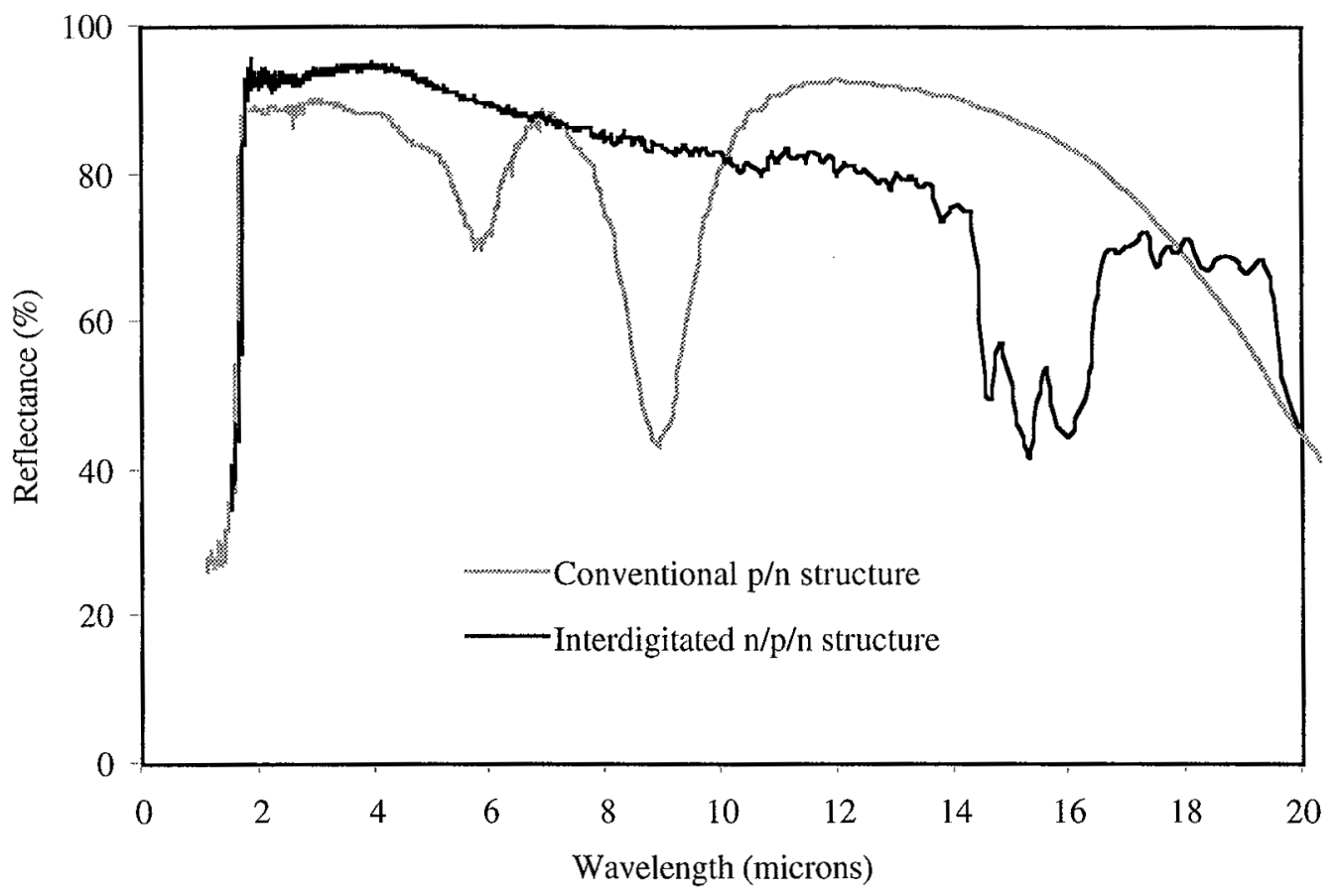

Figure 4. Reflectance comparison of conventional $p / n$ and interdigitated $n / p / n$ structures.

Table 1 lists the short circuit current density, FF, spectral utilization (Fu) and the product of FF and Fu for the five (5) devices previously described under a variety of blackbody temperatures. The spectral utilization is a ratio of the useful energy absorbed in the emitter and base divided by the total energy absorbed. Also shown is the change in the $\mathrm{FF}^{*} \mathrm{Fu}$ product compared to the $\mathrm{n} / \mathrm{p} / \mathrm{n}$ interdigitated device design. The $\mathrm{FF}{ }^{\star} \mathrm{Fu}$ product captures both the electrical efficiency and optical efficiency of the MIM device in a single, evenly weighted factor. The $p / n$ conventional MIM devices all show significantly lower combined efficiency, particularly at the lower emitter temperatures. The difference between the conventional and interdigitated $\mathrm{n} / \mathrm{p} / \mathrm{n} \mathrm{MIM}$ is smaller, particularly at the higher temperature emitters.

\section{$\underline{0.6 \mathrm{eV} \mathrm{n} / \mathrm{p} / \mathrm{n} \text { Cell Development }}$}

As was stated previously, the goal of this development effort is to develop a low bandgap MiM device suitable for operation with a low temperature radiator. After demonstration of the $0.74 \mathrm{eV} \mathrm{n} / \mathrm{p} / \mathrm{n}$ device, efforts shifted to development of $0.6 \mathrm{eV}$ and lower bandgap $\mathrm{n} / \mathrm{p} / \mathrm{n}$ structures. These device structures, being lattice mismatched to the InP substrate, use a proprietary buffer layer which has demonstrated reverse saturation current densities of $<4 \times 10^{-7} \mathrm{~A} / \mathrm{cm}^{2}$ in $\mathrm{p} / \mathrm{n} 0.6 \mathrm{eV}$ MIMs.

Several test structures have been fabricated, both conventional and interdigitated $n / p / n$ MIM designs. These devices have utilized $200 \AA$ tunnel junction layers. The data from these structures indicates that resistance in the thin tunnel junction does not limit the FF. A typical interdigitated $n / p / n$ design is shown in Figure 5. 


\begin{tabular}{|c|c|c|c|c|c|c|}
\hline MIM & $\begin{array}{c}\text { Trad } \\
{ }^{\circ} \mathrm{F}\end{array}$ & $\begin{array}{c}\mathrm{Jsc} \\
\mathrm{A} / \mathrm{cm}^{2}\end{array}$ & $F F$ & $\mathrm{Fu}$ & $F u^{\star} F F$ & $\begin{array}{c}\% \text { Change } \\
\text { Relative to } \\
468 \\
\end{array}$ \\
\hline \multirow[t]{3}{*}{$\begin{array}{c}40,0.3 \text { m, } 2 \times 10^{19} \text { p-type } \\
\text { emitter } \\
\text { p/n MIM } \\
\end{array}$} & 1750 & 0.68 & 0.746 & 0.197 & 0.147 & $-97 \%$ \\
\hline & 2250 & 2.85 & 0.69 & 0.389 & 0.268 & $-65 \%$ \\
\hline & 2500 & 4.65 & 0.63 & 0.472 & 0.297 & $-64 \%$ \\
\hline \multirow[t]{3}{*}{$\begin{array}{c}445,0.1 \_\mathrm{m}, 2 \times 10^{19} \mathrm{p} \text {-type } \\
\text { emitter } \\
\mathrm{p} / \mathrm{n} \text { MIM }\end{array}$} & 1750 & 0.68 & 0.731 & 0.232 & 0.17 & $-71 \%$ \\
\hline & 2250 & 2.85 & 0.67 & 0.443 & 0.297 & $-49 \%$ \\
\hline & 2500 & 4.65 & 0.6 & 0.526 & 0.316 & $-54 \%$ \\
\hline \multirow[t]{3}{*}{$\begin{array}{c}408,0.3 \text { m, } 1 \times 10^{18} \text { p-type } \\
\text { emitter } \\
\text { p/n MIM }\end{array}$} & 1750 & 0.68 & 0.5 & 0.272 & 0.136 & $-13 \%$ \\
\hline & 2250 & 2.85 & - & 0.499 & - & \\
\hline & 2500 & 4.65 & - & 0.583 & - & \\
\hline \multirow[t]{3}{*}{$\begin{array}{c}510,0.3 \text { _m, } 1 \times 10^{18} \text { n-type } \\
\text { emitter } \\
\text { n/p/n MIM } \\
\end{array}$} & 1750 & 0.68 & 0.754 & 0.296 & 0.223 & $-30 \%$ \\
\hline & 2250 & 2.85 & 0.744 & 0.508 & 0.378 & $-17 \%$ \\
\hline & 2500 & 4.65 & 0.740 & 0.584 & 0.432 & $-13 \%$ \\
\hline \multirow[t]{3}{*}{$\begin{array}{c}468,0.1 \text { _m, } 1 \times 10^{18} \text { n-type } \\
\text { emitter } \\
\text { n/p/n MIM } \\
\end{array}$} & 1750 & 0.68 & 0.754 & 0.384 & 0.29 & - \\
\hline & 2250 & 2.85 & 0.744 & 0.596 & 0.443 & - \\
\hline & 2500 & 4.65 & 0.740 & 0.660 & 0.488 & - \\
\hline
\end{tabular}

Table 1 - Summary of Fill Factor and Spectral Utilization Data for $0.74 \mathrm{eV} \mathrm{p/n}$ and n/p/n MIMs.

Figure 6 compares the reflectance test data from a $0.58 \mathrm{eV} \mathrm{n} / \mathrm{p} / \mathrm{n}$ structure, as grown material (as shown in Figure $5)$, to a processed cell from the same material. The cell includes a dual layer anti-reflective (AR) coating $(\mathrm{ZnS} / \mathrm{MgF})$ and $\mathrm{Cr} / \mathrm{Au}$ contact metallization. The structure has a gold BSR layer only. The data demonstrates a reduction in the reflectance of the cell beyond the InGaAs bandedge. This difference is due to several factors. The $\mathrm{Cr}$ adhesion layer for the front surface metallization reduces the reflectance in the $2-4 \mu \mathrm{m}$ region. Overlying that is an absorption peak near $3 \mu \mathrm{m}$ associated with water absorbed in the AR coating. The difference in reflectance shrinks to insignificant levels by approximately $7 \mu \mathrm{m}$. 


\begin{tabular}{|c|c|}
\hline $0.1 \mu \mathrm{m} \mathrm{n}++\operatorname{InGaAs}$ & Contact Layer \\
\hline $500 \AA n+\operatorname{lnPAs}$ & Front Window \\
\hline $0.3 \mu \mathrm{m} n+\operatorname{InGaAs}$ & Emitter \\
\hline $3.0 \mu \mathrm{m} \mathrm{p} / \mathrm{nGaAs}$ & Base \\
\hline $500 \AA \mathrm{p}+\ln \mathrm{n} A \mathrm{~s}$ & Back Window \\
\hline $200 \AA \AA p++\ln G a A s$ & \\
\hline $200 \AA \mathrm{n}++\ln \mathrm{GaAs}$ & minel Jun \\
\hline $500 \AA n+\ln P A s$ & Et ch St op \\
\hline $0.3 \mu \mathrm{m} \mathrm{n}+\operatorname{InGaAs}$ & Lateral Conduction Layer \\
\hline InPAs & Buffer Layer \\
\hline $\operatorname{InP}: \mathrm{Fe}$ & Substrate \\
\hline
\end{tabular}

Figure 5 - low bandgap $(<0.74 \mathrm{eV}) \mathrm{n} / \mathrm{p} / \mathrm{n}$ interdigitated MIM test structure

Figure 7 shows the external quantum efficiency for the $0.58 \mathrm{eV} \mathrm{n} / \mathrm{p} / \mathrm{n}$ interdigitated MIM device described above. The device has a dual layer AR coating and Au back surface reflector. This data is from the first attempt at producing this device. Continued development is expected to improve this encouraging start.

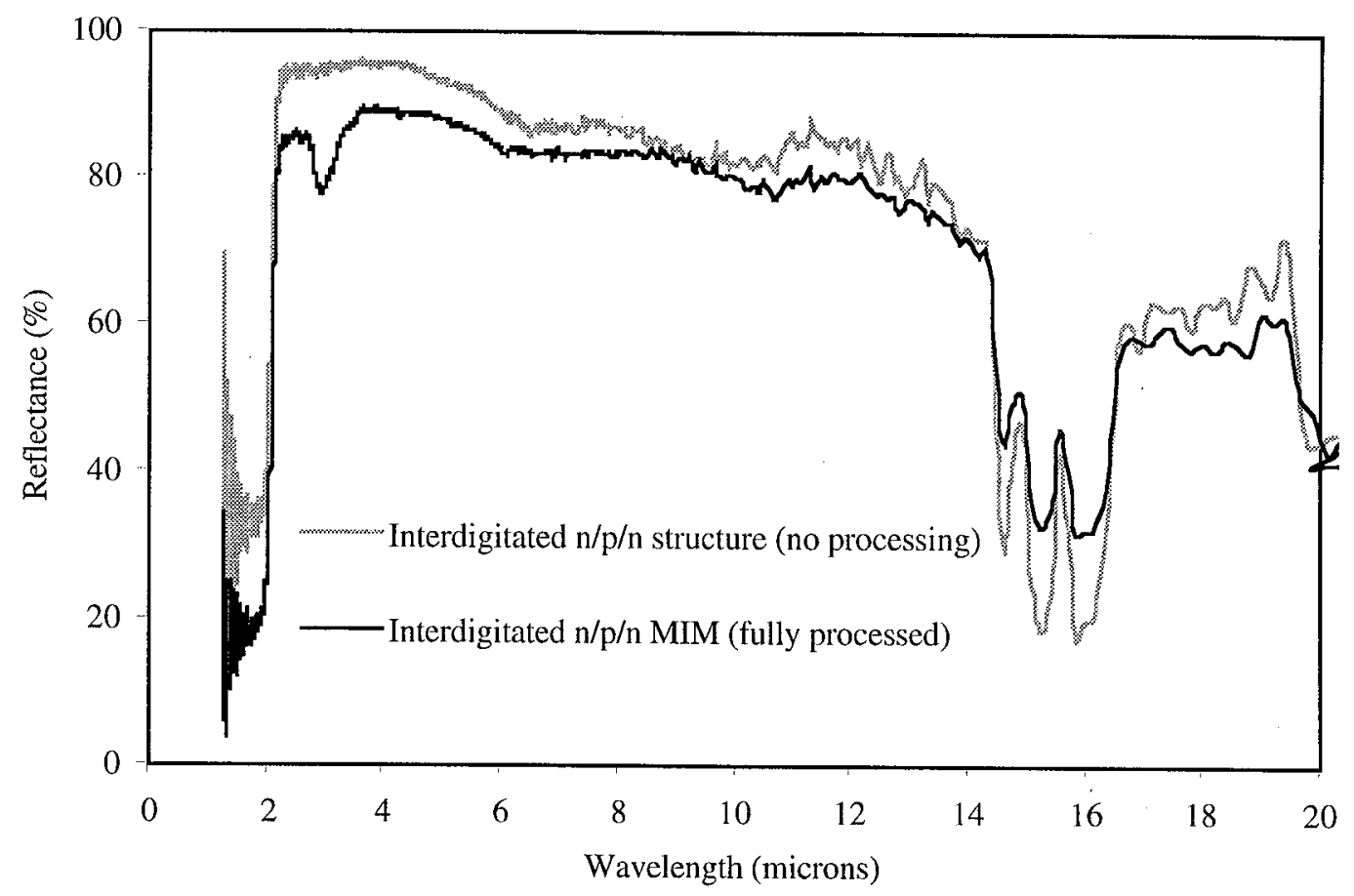

Figure 6 - Comparison of $0.58 \mathrm{eV}$ Cell and Structure Reflectance. 


\section{Conclusion}

A new tunnel junction MIM design has been described (pat. pend.) which offers the potential for higher power density and efficiency compared to $\mathrm{p} / \mathrm{n}$ conventional or interdigitated MIM devices. Both $0.74 \mathrm{eV}$ conventional and $0.58 \mathrm{eV}$ interdigitated $\mathrm{n} / \mathrm{p} / \mathrm{n}$ MIM devices have been demonstrated with encouraging results. The $0.58 \mathrm{eV}$ and 0.74 $\mathrm{eV}$ InGaAs devices have demonstrated reflectance's above $90 \%$ for wavelengths beyond the bandgap (>95\% for unprocessed structures).

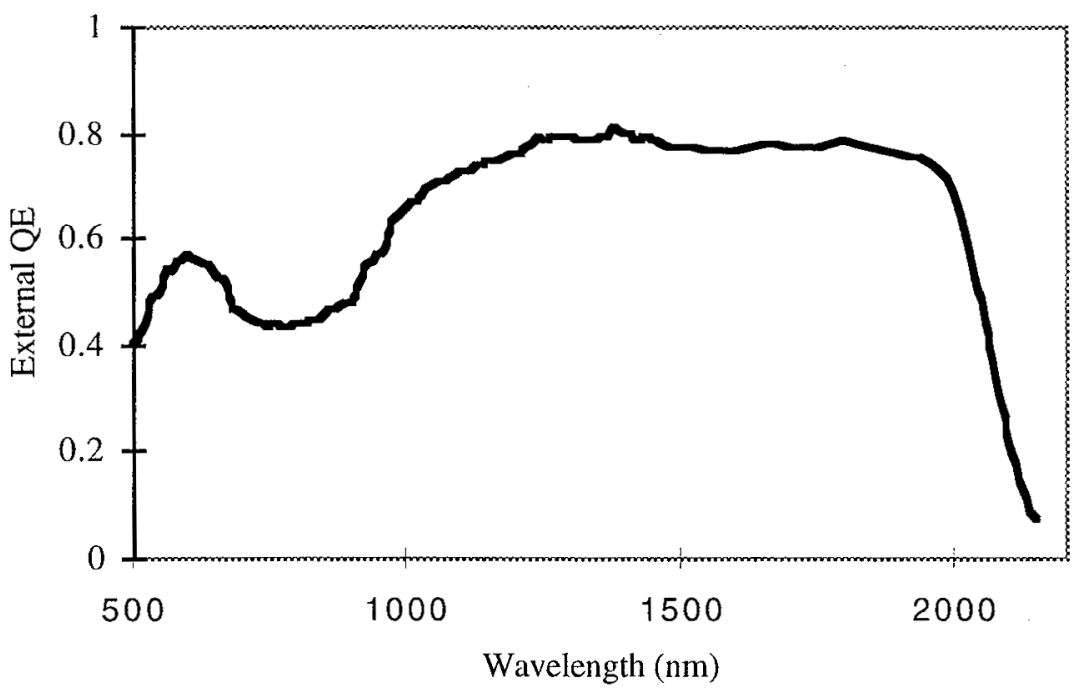

Figure 7 - External QE of $0.58 \mathrm{eV} \mathrm{n} / \mathrm{p} / \mathrm{n}$ Interdigitated MIM

Electrical measurements indicate minimal voltage drops across the tunnel junction $(<3 \mathrm{mV} / \mathrm{junction}$ under $1200 \mathrm{~K}$ blackbody illumination) and fill factors that are above $70 \%$ out to current densities $\left(\mathrm{J}_{\mathrm{sc}}\right)$ above $8 \mathrm{~A} / \mathrm{cm}^{2}$ for $0.74 \mathrm{eV}$ devices. The emphasis now shifts to optimizing the devices through reduction in tunnel junction layer thickness' (currently at 200 angstroms), active cell region optimization, grid design and new processing strategies. Care must be exercised in designing a fabrication process since these processes can seriously degrade the optical efficiency of the completed MIM device.

\section{References}

1) Proc. First NREL Conf. On TPV Generation of Electricity, AIP 321, 1994.

2) D.L. Chubb, "Reappraisal of Solid Selective Emitters," Proc. $21^{\text {st }}$ IEEE Photovoltaic Specialists Conference, pp. 1326-1342, 1990.

3) D.M. Wilt, et al., "InGaAs PV Device Development for TPV Power Systems," $1^{\text {st }}$ NREL Conf. On TPV Gen. Of Elect, pp. 210, AIP 321, 1994.

4) W.E. Horne, et al., "IR Filters for TPV Convertor Modules", Proc. $2^{\text {nd }}$ NREL Conf. On TPV Gen. Of Elect, pp. 35, AlP 358, 1995.

5) G.W. Charache, et al., "Thermophotovoltaic Devices Utilizing Back Surface Reflector for Spectral Control," Proc. $2^{\text {nd }}$ NREL Conf. On TPV Gen. Of Elect, pp. 191, AIP 358, 1995.

6) P.A. Iles and C.L. Chu, "TPV Cells with High BSR," Proc. $2^{\text {nd }}$ NREL Conf. On TPV Gen. Of Elect, pp. 361, AIP 358, 1995.

7) D.M. Wilt, et al., "Electrical and Optical Performance Characteristics of $0.74 \mathrm{eV} \mathrm{p} / \mathrm{n}$ InGaAs Monolithic Interconnected Modules," Proc. 3rd NREL Conf. On TPV Gen. Of Elect, pp. 237, AIP 401, 1997.

8) J.S. Ward, et al., "A Novel Design for Monolithically Interconnected Modules (MIMs) for Thermophotovoltaic 
Power Conversion," Proc. 3rd NREL Conf. On TPV Gen. Of Elect, pp. 227, AIP 401, 1997.

9) C.T. Ballinger, et al., "Monte Carlo Analysis of a MIMs Device with a Back Surface Reflector," Proc. 4th NREL Conf. On TPV Gen. Of Elect, AIP, 1998. 